stiffness $(n=11)$ an increase of ${ }^{18}$ F-FDG uptake in shoulders was observed. Twenty-three patients of thirty-two patients $(71.8 \%)$ with ${ }^{18} \mathrm{~F}-\mathrm{FDG}$ uptake in hips had pelvic girdle pain. The remaining localizations of ${ }^{18} \mathrm{~F}-\mathrm{FDG}$ uptake in PET/CT scans did not show significant correlations with clinical symptoms.

\begin{tabular}{|l|l|l|l|}
\cline { 2 - 4 } \multicolumn{1}{l|}{} & \multicolumn{3}{c|}{ F-FDG uptake } \\
\hline $\begin{array}{l}\text { Clinical manifestation/location of } \\
\text { FDG uptake }\end{array}$ & Positive, $\mathbf{n} / \mathbf{N}(\%)$ & Negative, $\mathbf{n} / \mathbf{N}(\%)$ & $\mathbf{P}$ \\
\hline Shoulder girdle pain (n=40)/ & & & \\
\hline Shoulder & $27 / 45(60.0)$ & $13 / 30(43.3)$ & 0.16 \\
\hline Sternoclavicular joints & $22 / 33(66.7)$ & $18 / 42(42.9)$ & 0.04 \\
\hline Cervical interspinous bursae & $6 / 9(66.7)$ & $34 / 66(51.5)$ & 0.49 \\
\hline Neck pain (n=12)/ & & & \\
\hline Shoulder & $8 / 45(17.8)$ & $4 / 30(13.3)$ & 0.61 \\
\hline Cervical interspinous bursae & $2 / 9(22.2)$ & $10 / 66(15.5)$ & 0.63 \\
\hline Morning stiffness (n=11)/ & & & \\
\hline Shoulder & $11 / 45(24.4)$ & $0 / 30(0.0)$ & 0.002 \\
\hline Sternoclavicular joints & $7 / 33(21.2)$ & $4 / 42(9.5)$ & 0.20 \\
\hline Cervical interspinous bursae & $3 / 9(33.3)$ & $8 / 66(12.1)$ & 0.12 \\
\hline Pelvic girdle pain (n= 42)/ & & & \\
\hline Hips & $23 / 32(71.8)$ & $19 / 43(44.2)$ & 0.02 \\
\hline Lumbar interspinous bursae & $18 / 29(62.1)$ & $24 / 46(52.2)$ & 0.40 \\
\hline Subtrochanteric bursae & $11 / 20(55.0)$ & $31 / 55(56.4)$ & 0.92 \\
\hline Ischial tuberosities & $10 / 19(52.6)$ & $32 / 56(57.1)$ & 0.73 \\
\hline Pubic symphysis & $3 / 4(75.0)$ & $39 / 71(54.9)$ & 0.63 \\
\hline $\begin{array}{l}\text { Inflammatory low back pain } \\
\text { (n=20)/ }\end{array}$ & & & \\
\hline Hips & $10 / 32(31.3)$ & $10 / 43(23.3)$ & 0.44 \\
\hline Lumbar interspinous bursae & $10 / 29(34.5)$ & $10 / 46(21.7)$ & 0.22 \\
\hline Ischial tuberosities & $3 / 19(15.8)$ & $17 / 56(30.4)$ & 0.26 \\
\hline Subtrochanteric bursae & $7 / 20(35.0)$ & $13 / 55(23.6)$ & 0.33 \\
\hline Pubic symphysis & $3 / 4(75.0)$ & $17 / 71(23.9)$ & 0.06 \\
\hline Diffuse lower limb pain (n=35)/ & & & \\
\hline Knees & $16 / 33(48.5)$ & $19 / 42(45.2)$ & 0.78 \\
\hline Subtrochanteric bursae & $8 / 20(40.0)$ & $27 / 55(49,1)$ & 0.49 \\
\hline Ischial tuberosities & $9 / 19(47.4)$ & $26 / 56(46.4)$ & 0.94 \\
\hline Hips & $15 / 32(46.9)$ & $20 / 43(46.5)$ & 0.98 \\
\hline & & & \\
\hline
\end{tabular}

Conclusions: In patients with PMR, the presence of shoulder girdle pain seems to correlate with $\mathrm{F}^{18}{ }^{18} \mathrm{FDG}$ uptake in sternoclavicular joints, morning stiffness with ${ }^{18} \mathrm{~F}$-FDG uptake in shoulders and pelvic girdle pain with ${ }^{18} \mathrm{FDG}$ uptake in hips. No other significant correlations were found between any other symptom and ${ }^{18} \mathrm{~F}$ FDG uptake.

Disclosure of Interest: None declared

DOI: 10.1136/annrheumdis-2018-eular.4968

\section{SAT0650 MUSCULOSKELETAL ULTRASOUND IN FIRST DEGREE RELATIVES OF RHEUMATOID ARTHRITIS PATIENTS}

E. Soliman ${ }^{1,2} .{ }^{1}$ Internal Medicine, Rheumatology and Clinical Immunology., Faculty of Medicine, Alexandria, Egypt, ${ }^{2}$ EULAR Certified MSUS Trainer. Rheumatology postgraduate diploma student, University of South Wales, South UK

Background: Preclinical phase of rheumatoid arthritis (RA) is characterised by a state of autoimmunity and inflammation. MSUS is known for its ability to detect subclinical synovitis, but changes in first degree relatives (FDR) are not yet defined.

Objectives: To investigate the presence of abnormal MSUS findings in FDR of RA who are free of clinical disease.

Methods: Study included 20 RA patients, and 25 of their FDR without evidence of arthritis. All were subjected to full history taking with special emphasis on joint symptoms, and joint examination. Measurements of ESR, CRP, RF and anti-CCP were performed in all and MSUS scan using the 7 joint ultrasonography (US7) score $^{1}$

Results: Mean age in FDR $33.1 \pm 13.4$ years, and in RA was $39.50 \pm 13.43$ years with a mean disease duration of $11.95 \pm 8.36$ years. All RA $(100 \%)$ had symmetrical, polyarthralgia and/or arthritis, mostly involving small joints of hands and feet. $8 / 25$ FDR (32\%) had arthralgia that included different joints. While 17/25 FDR $(68 \%)$ were asymptomatic. None of FDR had arthritis as it was an exclusion criteria. MSUS findings were detected in 16/20 (80\%) RA and in 10/25 (40\%) FDR. Of whom $3 / 10$ FDR $(12 \%)$ had arthralgia and $7 / 10(28 \%)$ were asymptomatic. Synovitis was the commonest MSUS finding in RA $(n=16,80 \%)$, and in their FDR $(n=10,40 \%)$. Tenosynovitis was present in 5 (25\%) RA and only one (4\%) FDR. Erosions were detected in $9(45 \%)$ of RA and one (4\%) FDR in the 2 nd MCP. In RA the wrist was most common joint to be involved on MSUS $(n=14,70 \%)$, followed by 2nd MCP and 2nd MTP joints in 11 (55\%), 5th MTP joint in 8 (40\%), 3rd MCP joint in $6(30 \%)$, 2nd PIP joint in $4(20 \%)$, with least involvement in the 3rd PIP joint in $3(15 \%)$ of RA. In FDR the wrist was also the most commonly involved joint on MSUS and 2nd MTP joint in $6(24 \%)$, followed by 2 nd MCP joint in only 1 $(4 \%)$. Whereas, the 3rd MCP, 2nd and 3rd PIPs and 5th MTP joints were spared.
US7 score in RA and FDR are shown in table 1. US7 erosion score correlated significantly with disease duration in RA. Anti-CCP significantly correlated with all parameters of US7 and RF with the tenosynovitis GS (grey scale) score. While, in FDR there was no statistical significant correlation between US7 score with any of the inflammatory or seromarkers.

Abstract SAT0650 - Table 1. US7 Joint score in RA and FDR

\begin{tabular}{lccc}
\hline US7 score & RA $(\mathrm{n}=20)$ & FDR $(\mathrm{n}=25)$ & $\mathrm{P}$ \\
\hline Synovitis GS & $5.15 \pm 4.26$ & $0.64 \pm 1.04$ & $<0.001^{*}$ \\
Synovitis PD & $2.05 \pm 2.54$ & $0.24 \pm 0.83$ & $0.003^{*}$ \\
Tenosynovitis GS & $0.35 \pm 0.75$ & $0.04 \pm 0.20$ & $0.040^{*}$ \\
Tenosynovitis PD & $0.30 \pm 0.80$ & $0.0 \pm 0.0$ & $0.048^{*}$ \\
Erosions & $1.60 \pm 3.10$ & $0.04 \pm 0.20$ & $0.001^{*}$ \\
Total score & $9.45 \pm 7.21$ & $0.96 \pm 2.01$ & $<0.001^{*}$ \\
\hline
\end{tabular}

Showed values are mean $\pm S D$. $p$ : $p$ values for Mann Whitney test for comparing between the two groups*: Statistically significant at $p \leq 0.05$

Conclusions: This study confirms the presence of inflammatory synovial changes in FDR of RA who are free of clinical disease. This strengthens the concept of FDR as pre-RA. US7 score is a useful screening tool to identify subclinical synovitis in at-risk individuals. While in RA, US7 score is significantly correlated to disease duration and autoantibodies. More long term studies on FDR are needed for establishing the predictive value of abnormal MSUS findings for the development of persistent arthritis.

\section{REFERENCE:}

[1] Backhaus $\mathrm{M}$, et al. Evaluation of a novel 7-joint ultrasound score in daily rheumatologic practice: A pilot project. Arthritis Care Res 2009;61 (9):1194-201.

Disclosure of Interest: None declared

DOI: 10.1136/annrheumdis-2018-eular.2349

\section{SAT0651 CAROTID ULTRASOUND IN PATIENTS WITH ARTHRITIS: ¿IN WHICH PATIENTS DOES IT RE- STRATIFY CV RISK?}

F. Sivera, N. Martinez-Alberola, R. Martin-Domenech, G. Albert-Espi, C. Fernandez-Carballido, T. Pedraz-Penalva. Dpt Reumatology, Hospital General Uiversitario De Elda, Elda, Spain

Objectives: To explore in which patients with inflammatory rheumatic disease, the findings in a carotid ultrasound result in a change in cardiovascular (CV) risk stratification as compared to the $\mathrm{CV}$ risk measured with the SCORE index.

Methods: Longitudinal prospective study in patients included in a program geared at CV risk factor screening followed by optimisation of their treatment. Patients with rheumatoid arthritis (RA), spondyloarthritis (SpA) and psoriatic arthritis (PsA) were included in the program. In a nurse-led single-visit, the exis tence and adequate control of classic $\mathrm{CV}$ risk factors were recorded. SCORE index was calculated and then modified according to EULAR recommendations. CV risks was stratified according to European guidelines. A carotid ultrasound was performed in patients with a low, intermediate or high-risk stratification in order to assess intimal-media thickness (IMT) and plaques. If plaques were detected, CV risk was re-stratified to very high risk.

From this program, patients who had completed the baseline evaluation and the carotid ultrasound were selected. The characteristics of patients with findings in carotid ultrasound that allowed re-stratification to those without these findings were compared.

Results: A total of 181 patients have completed the baseline work-up, including the carotid ultrasound. $122(67 \%)$ of the patients were women with a mean age of $55( \pm 11)$ years of age. Included patients had RA $(n=96,53 \%), \operatorname{SpA}(n=37,20 \%)$ or PsA ( $n=48,27 \%)$

A diagnosis of DM was performed in $19(10 \%)$, hypertension in $78(43 \%)$ and hypercholesterolemia in $92(51 \%) ; 38(21 \%)$ were active smokers and $63(35 \%)$ were obese $(\mathrm{BMI}>30)$. Mean SCORE index (modified according to EULAR recommendations) was $2.4( \pm 1.7)$. Risk stratification before ultrasound was 145 $(80 \%)$ patients with intermediate risk and $36(20 \%)$ with high risk.

Carotid ultrasound imaging showed plaques in 43 patients (bilaterally in 14). In these, risk was re-stratified as very high risk. Overall, 11 patients showed a thick ening of IMT; all presented plaques as well. Final risk stratification after including 
the carotid ultrasound findings showed 110 patients with intermediate risk, 28 with high risk and 43 with a very high risk.

In table 1, the characteristics of the 43 patients whose carotid ultrasound findings resulted in a risk re-stratification vs the 138 with no risk modification.

\begin{tabular}{lcc}
\hline & $\begin{array}{c}\text { Risk modification due to } \\
\text { pathologic carotid } \\
\text { ultrasound }(\mathbf{n}=\mathbf{4 3})\end{array}$ & $\begin{array}{c}\text { No risk modification due to } \\
\text { pathologic carotid ultrasound } \\
(\mathbf{n}=138)\end{array}$ \\
\hline Sex (Woman) & $32(74 \%)$ & $90(65 \%)$ \\
Age (years) & $58,1( \pm 9)$ & $53,5( \pm 12)^{*}$ \\
Disease & $28(65 \%)$ & $68(49 \%)$ \\
RA $(n=96)$ & $6(14 \%)$ & $31(22 \%)$ \\
SpA $(n=37)$ & $9(21 \%)$ & $39(28 \%)$ \\
PsA ( $n=48)$ & & \\
DM & $4(9 \%)$ & $15(11 \%)$ \\
High blood pressure & $24(56 \%)$ & $54(39 \%)$ \\
Hypercholesterolemia & $30(70 \%)$ & $59(43 \%)^{*}$ \\
Smoker & $12(28 \%)$ & $26(19 \%)$ \\
Obesity & $31(72 \%)$ & $87(63 \%)$ \\
Modified SCORE & $2,7( \pm 1,6)$ & $2,3( \pm 1,7)$ \\
\hline${ }^{*}$ p $<0.05$ between group comparison &
\end{tabular}

Conclusions: Patients with risk modification due to carotid ultrasound findings were older and were more frequently hypercholesterolemic. Performing a carotid ultrasound in these patients seems to offer especially relevant information.

Disclosure of Interest: None declared

DOI: 10.1136/annrheumdis-2018-eular.4867

\section{SAT0652 STUDY OF NAIL UNIT WITH ULTRASONOGRAPHY IN SEVERAL RHEUMATOLOGICAL CONDITIONS: A CROSS SECTIONAL STUDY OF DISTAL INTERPHALANGEAL JOINT AND NAIL}

G. Adami, E. Vantaggiato, C. Benini, A. Fassio, A. Giollo, G. Orsolini, L. Idolazzi, D. Gatti. Rheumatology Unit, University of Verona, Verona, Italy

Background: The ultrasonography (US) is a feasible technique when you refer to the peripheral small joints and also to the nail. ${ }^{1}$ DIP joints are not only affected by inflammatory disease and a more frequent condition is osteoarthritis (OA). The bone and synovial changes due to this condition are very similar to the ones of PSA especially regarding osteoproliferative lesions.

Objectives: The aim of our study was exploring through imaging the changes of nail and enthesis of extensor tendon of the finger in inflammatory and degenerative conditions in order to find structural differences of nail and DIP.

Methods: This is an observational study on PSO, PSA, RA or OA patients. A control group of 50 healthy volunteers was used for comparison. Diagnosis was based on clinical or scientific criteria, such as CASPAR or EULAR/ACR were applicable. The study sample included 203 individual. The ultrasonographers were blind to clinical data and diagnosis of the patient. The ultrasound examination was done with a GE Logiq S8. The structural alterations of the plate were evaluated using a semiquantitative score for the magnitude of the alteration. The score provides values from 0 (no alteration) to 3 (severly altered). A semiquantitative approach was also used for evaluation of the power Doppler signal.

Results: The study sample was composed by 51 patients affected by PsA, 31 affected by PSO group, 37 subjects with RA, 34 with OA and $50 \mathrm{HC}$. The analysis of nail bed PDUS revealed an unusual trend for patients affected by OA who showed a prevalence of lesions of every grade but a lower rate of normal cases. The evaluation of the PDUS of the enthesis revealed that patients affected by PsA have an increased rate of PDUS signal at the enthesis of the extensor tendon. Considering nail plate $\mathrm{HC}$ showed a strong difference ( $\mathrm{p}$ value $<0.001$ ) vs all groups except for patients affected by RA. Regarding nail bed thickness HC showed difference only if compared with PSA or OA group. $\mathrm{P}$ values are reported in table 1.

\begin{tabular}{llccccc}
\hline & & PSO & PSA & RA & OA & HC \\
\hline Nail plate & PSO & $/ /$ & 0.99 & 0.021 & 0.99 & $<0.001$ \\
Thickness & PSA & 0.99 & $/ /$ & 0.002 & 0.99 & $<0.001$ \\
& RA & 0.021 & 0.002 & $/ /$ & 0.06 & 0.06 \\
& OA & 0.99 & 0.99 & 0.06 & $/ /$ & $<0.001$ \\
& HC & $<0.001$ & $<0.001$ & 0.06 & $<0.001$ & $/ /$ \\
Nail bed & PSO & $/ /$ & 0.99 & 0.003 & $<0.001$ & 0.15 \\
Thickness & PSA & 0.99 & $/ /$ & $<0.001$ & $<0.001$ & 0.002 \\
& RA & 0.003 & $<0.001$ & $/ /$ & 0.69 & 0.12 \\
& OA & $<0.001$ & $<0.001$ & 0.69 & $/ /$ & 0.012 \\
& HC & 0.15 & 0.002 & 0.12 & 0.012 & $/ /$ \\
\hline
\end{tabular}

Conclusions: The data support the concept that nail enthesis unit is in some way involved in different pathological conditions. No exclusive feature belongs only to one or another disease, but the data provided suggested that peculiar lesions might be found only in certain disease and in certain structures, like the entheses.
The US of the nail should be considered as one of the possible and promising approach in the study of these structures.

\section{REFERENCE:}

[1] Arbault A, Devilliers $H$, Laroche D, et al. Reliability, validity and feasibility of nail ultrasonography in psoriatic arthritis. Jt Bone Spine Rev Rhum 2016;83:539-44. doi:10.1016/j.jbspin.2015.11.004

Disclosure of Interest: None declared

DOI: 10.1136/annrheumdis-2018-eular.6992

\section{SAT0653 RELATIONSHIP BETWEEN CARDIAC VALVULAR CALCIFICATION, CAROTID ATHEROSCLEROSIS, AND CORONARY CALCIFICATION IN PATIENTS WITH RHEUMATOID ARTHRITIS}

H. Udachkina, D. Novikova, T. Popkova, E. Markelova, I. Kirillova, E. Gerasimova. V.A. Nasonova Research Institute of Rheumatology, Moscow, Russian Federation

Background: The prevalence and relationship of VC with arterial atherosclerosis in patients with rheumatoid arthritis (RA) is under-investigated.

Objectives: investigate the prevalence of $\mathrm{VC}$ in patients with RA and its relationship with carotid atherosclerosis (CA) and coronary artery calcification (CAC).

Methods: Study population was consisted of 128 adult patients $(65.6 \%$ women, age $55^{43 ; 61}$ years) with RA according to ACR/EULAR criteria (disease duration $6^{5 ; 18}$ month) with moderate/high RA activity (DAS28 5.3 [5.0; 6.1]). Arterial hypertension $(\mathrm{AH})$ was found in $64 \%$, ischaemic heart disease (IHD) - in $14 \%$, dyslipidemia - in $54.7 \%$, smoking - in $20.3 \%$, diabetes mellitus type 2 - in $7 \%$, myocardial infarction - in $1.6 \%$, stroke - in $1.6 \%$. Cardiac VC was evaluated by transthoracic echocardiography; CAC scoring was done with 32-row scanner by standard Agatston method; CA was evaluated with duplex ultrasound.

Results: Patients were divided on 3 groups depending on valve condition: normal $(34.3 \%)$; leaves thickening $(30.5 \%)$; VC $(35.25 \%)$. The VC group consisted of isolated mitral VC - in 11\%, isolated aortic VC - in 51\%, calcification of both valve in $38 \%$. Mitral regurgitation (3 degree) was detected in $0.8 \%$ patient, mitral stenosis (mild) $-0.8 \%$, aortic regurgitation (1 degree) - in $25 \%$, aortic stenosis (mild) in $0.8 \%$. Age, BMI, SBP and frequency of $\mathrm{AH}, \mathrm{IHD}, \mathrm{CA}, \mathrm{CAC}$ significant increased from 1 to 3 group $(p<0.05)$. There was no significant difference in the sex, lipid levels, Rg-stage, RA duration and level of parameters of RA activity (DAS28, CRP ESR) between investigated groups.

\begin{tabular}{lccc}
\hline & $\begin{array}{c}\text { Normal valve } \\
(\mathrm{n}=44)\end{array}$ & $\begin{array}{c}\text { Thickening } \\
(\mathrm{n}=39)\end{array}$ & $\begin{array}{c}\text { Calcification } \\
(\mathrm{n}=45)\end{array}$ \\
\hline $\mathrm{Age}$ & $39.5^{29 ; 51}$ & $56.5[51.5 ; 62]$ & $60^{57 ; 67}$ * \\
$\mathrm{BMI}$ & $23.4[21.4 ; 28.6]$ & $26.3[23.7 ; 29.3]$ & $27.2^{25 ; 31 *}$ \\
$\mathrm{SBP}$ & $120^{100 ; 130}$ & $120^{110 ; 134}$ & $130^{120 ; 140 *}$ \\
$\mathrm{AH}$ & $19(43.2)$ & $23(59)$ & $40(88.9) *$ \\
$\mathrm{IHD}$ & $1(2.3)$ & $6(15.4)$ & $11(24.4) *$ \\
$\mathrm{CA}$ & $12(27.3)$ & $30(77)$ & $39(86.7)$ * \\
CAC & $8(18.2)$ & $16(41)$ & $32(71.1) *$ \\
\hline Note: Data are expressed as median $[25$ percentile;75 percentile] for continuous variables
\end{tabular}

and as a number $(\%)$ for the categorical variables. ${ }^{*}$ Difference for trend $(p<0.05)$

Conclusions: Among RA patients, more than half have a modified valve struc ture and in $1 / 3$ of them VC. The presence of VC is correlated with traditional cardiovascular risk factors, but not with lipid levels, activity and severity of RA. The probability of CA and CAC presence is significantly increased when there is VC. Disclosure of Interest: None declared DOI: 10.1136/annrheumdis-2018-eular.5447

\section{SAT0654 ASSOCIATION OF PREDNISONE AND ANTIMALARIALS AND ECHOCARDIOGRAPHIC FINDINGS IN ASYMPTOMATIC CARDIOVASCULAR PATIENTS WITH SLE}

I. Jochims, L.M.H. Mota, L. Muniz , D.F. Vasconcelos, L.L. Santos-Neto. UNIVERSITY OF BRASILIA, Brasilia, Brazil

Background: Systemic lupus erythematosus (SLE) is an autoimmune inflammatory disease that presents with increase of cardiovascular risk. Echocardiogram can detect morphofunctional cardiac changes and predict clinical outcomes in patients with SLE1.

Objectives: To evaluate echocardiographic morphofunctional parameters in women with SLE, using conventional echocardiogram and to relate the echocardiographic findings to disease-related factors and therapeutics.

Methods: We have selected 51 women with SLE, without cardiovascular symptoms, under regular medical follow-up. Patients who had limitations to do echocardiography, smokers, and those with a creatinine level higher than $1.5 \mathrm{mg} / \mathrm{dL}$ were 